\title{
Infrared Emission Spectra of Flames
}

\author{
By Earle K. Plyler and Curtis J. Humphreys
}

\begin{abstract}
The infrared emission spectra of a hydrogen flame and of a natural gas flame have been compared in the region from $1.7 \mu$ to $24 \mu$. Emission bands have been observed at $1.87 \mu, 2.78 \mu$, $4.37 \mu, 6.26 \mu$, and $15 \mu$ that are produced by molecules of $\mathrm{H}_{2} \mathrm{O}$ and $\mathrm{CO}_{2}$. Another band at $3.316 \mu$ is attributed to methane. From $3.0 \mu$ to $3.8 \mu$ there are a number of rotational lines, some of which may be produced by $\mathrm{OH}$ and others by $\mathrm{H}_{2} \mathrm{O}$ molecules. As the temperature of the flame was increased, the rotational lines became more intense. Five lines in the region from $3.4 \mu$ to $3.8 \mu$ agree closely in position with the predicted rotational lines of the $P$ branch of the $2 \rightarrow 1$ vibrational band of $\mathrm{OH}$. These lines correspond to values of $K$ equal to 11,12 , 13, 14, and 15. Wave numbers of some of the observed rotational lines were found to show a good correspondence with predicted values for $K$ equal to 11 to 36 , for lines extending from $9 \mu$ to $24 \mu$. In addition to this series of lines, there are other lines that are produced by the rotational states of $\mathrm{H}_{2} \mathrm{O}$ molecule. A discussion is included of the various methods of observing flame spectra.
\end{abstract}

\section{Introduction}

In the February 1948 number of the Journal of Research $^{2}$ there is an article on the emission spectra from a Bunsen flame. In that work it was shown that nearly all the emission spectra from the Bunsen flame were produced by $\mathrm{H}_{2} \mathrm{O}$ and $\mathrm{CO}_{2}$ molecules. The $\mathrm{CO}_{2}$ spectrum has bands in the regions of $4.4 \mu$ and $15 \mu$. The $\mathrm{CO}_{2}$ emission in the $15-\mu$ region is composed of at least three bands with frequencies of 667,668 , and $721 \mathrm{~cm}^{-1}$. These frequencies correspond to the changes in known energy levels. The transitions are $\left(01^{1} 0\right)$ to $\left(00^{\circ} 0\right),\left(02^{2} 0\right)$ to $\left(01^{1} 0\right)$, and $\left(10^{0} 0\right)$ to $\left(01^{1} 0\right)$. A discussion of the 15- $\mu$ emission of $\mathrm{CO}_{2}$ molecule has been given in a recent report. ${ }^{3}$ Nearly all the energy in the region of $2.7 \mu$ is radiated by the $\mathrm{H}_{2} \mathrm{O}$ molecule. Additional observations included the strong band of water vapor at $6.26 \mu$ in the emission spectrum, and many rotational lines extending from $10 \mu$ to $24 \mu$.

In the region of $2.8 \mu$ to $3.2 \mu$, there are 15 lines that have been attributed to the $\mathrm{H}_{2} \mathrm{O}$ molecule. In order to measure the spectrum in the $3-\mu$ region

\footnotetext{
1 The results of this paper were reported, in part, at the meeting of the Optical Society of America in October 1947.

2 E. K. Plyler, J. Research NBS 40, 113 (1948) RP1860.

${ }^{3}$ E. K. Plyler, Science 107, 48 (1948).
}

under different conditions of burning, a commercial gas-oxygen torch was used. The gas and oxygen were completely mixed before burning to produce a smooth, narrow, quiet flame $5 \mathrm{in}$. high on a port about $1 \mathrm{~mm}$ in diameter. The emission spectra of a gas-oxygen flame and a hydrogen-oxygen flame have been measured and the results compared.

\section{Experimental Work}

A Perkin-Elmer infrared spectrometer, with interchangeable prisms of $\mathrm{LiF}, \mathrm{NaCl}$, and $\mathrm{KBr}$, was used as the resolving instrument. Natural gas containing about 88 percent of methane was burned in a gas-oxygen torch, and the flame was changed by varying the amount of oxygen. This caused the flame temperature to be different, with a corresponding effect on the relative intensities of the bands. Some of the bands would increase in intensity and others would decrease in intensity, as the temperature was increased.

Figure 1 shows the emission bands from the flame of a gas-oxygen torch. Natural gas was burned with $\mathrm{O}_{2}$ in considerable amounts, giving rise to a hot flame. The zero branch of the $\mathrm{H}_{2} \mathrm{O}$ combination band is found to be at $1.87 \mu$, and the $P$ and $R$ branches at $1.95 \mu$ and $1.78 \mu$, respec- 


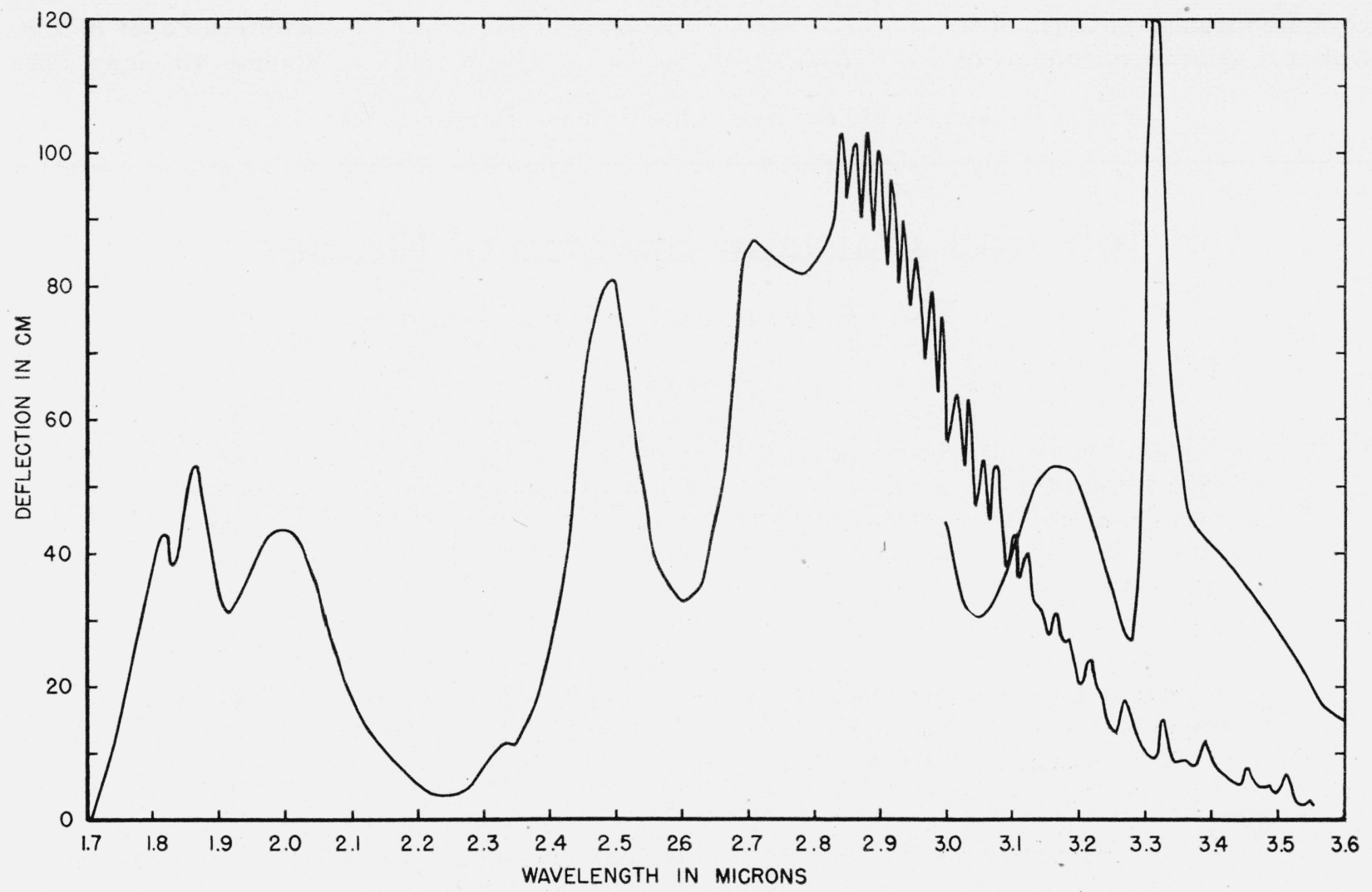

FIGURE 1. Infrared emission spectrum of a natural gas-oxygen flame.

The spectrometer slits were $0.18 \mathrm{~mm}$ in width, and an LiF prism was used. The methane band at $3.3 \mu$ was measured from a gas-air flame with cone of flame focused on spectrometer slit, and the slits were $0.25 \mathrm{~mm}$ in width.

tively are also resolved from the $Q$ branch. However, the resolution of the $\mathrm{LiF}$ prism was not sufficient for resolving any of the rotational structure. In the region from $2.84 \mu$ to $3.55 \mu$ there are many rotational lines. When less oxygen is used in the flame the lines from $2.84 \mu$ to $3.1 \mu$ stand out more prominently, and the faint lines in the region from $3.1 \mu$ to $3.55 \mu$ disappear. The intense band with a sharp maximum at $3.315 \mu$ was observed when small amounts of oxygen were introduced in the burner and a large cone was present in the flame. The region of the cone was focused on the entrance slit of the spectrometer. The zero branch is sharp and of good intensity. The $R$ branch is observed and is of maximum intensity at $3.16 \mu$, and is well separated from the zero branch.

In figure 2 the emission spectra of the hydrogen flame are shown for the spectral region of 1.7 to $3.9 \mu$. The $1.87-\mu$ maximum, which is the zero branch of a combination band of the $\mathrm{H}_{2} \mathrm{O}$ molecule, is quite intense. The $P$ branch is relatively less intense in the hydrogen flame than in the gas flame. The greater intensity of the gas flame may be caused by the radiation of the $\mathrm{CO}_{2}$ molecule in the region of $2 \mu$.

The zero branch at $2.71 \mu$ is somewhat reduced by the absorption of the $\mathrm{CO}_{2}$ and $\mathrm{H}_{2} \mathrm{O}$ molecules in the air. However, in figures 1 and 2 there has not been any correction applied for the atmospheric absorption. A comparison of the two figures indicates that there is considerable emission from $\mathrm{CO}_{2}$ in this region. The $R$ branch of the $\mathrm{H}_{2} \mathrm{O}$ band has the greatest intensity at $2.5 \mu$ and the $P$ branch at about $2.9 \mu$. As shown in figure 2 , the rotational lines in the $P$ branch of the $2.7 \mu-\mathrm{H}_{2} \mathrm{O}$ emission band are well marked, and 19 lines are observed in the region from $2.80 \mu$ to $3.25 \mu$. The slits of the spectrometer were 0.185 $\mathrm{mm}$ wide, and the flame had considerable oxygen.

When the flame was made hotter by increasing the oxygen by a small amount, these lines were less conspicuous. The flame was adjusted so that 
the lines were of greatest contrast to the background, and they were observed with a somewhat narrower slit. Under these conditions it was found that several of the lines had bulges on their sides. It was not possible to completely separate the complex structures with the LiF prism, but it is highly probable that many other lines could be observed in this region if higher resolution were employed.

The curve marked $b$ in figure 2 represents the flame spectrum from $3.0 \mu$ to $3.4 \mu$ when the oxygen is increased. The greater deflections are produced, in part, by increasing the amplication of the thermocouple output by about 50 percent. Under the different flame conditions the rotational components show a considerable variation in intensity. At wavelengths beyond $3.1 \mu$ the lines have greater intensity, and it has been possible to extend the observation of rotational structure to $3.8 \mu$. Curve $c$ in figure 2 was measured by increasing the slits to $0.25 \mathrm{~mm}$ and increasing the amplication by a factor of two compared to the value used in the region from $1.7 \mu$ to $3.4 \mu$. The wavelengths of the rotational lines are listed in section III.

The infrared emission in the region from $3.5 \mu$ to $5.0 \mu$ from the flame was studied, when mixtures of natural gas and oxygen were used. It was found that the emitted energy could be more than doubled by increasing the oxygen. The corrections for the atmospheric absorption and also the self absorption of the flame were calculated from observed data. By passing radiation of one flame through another flame, it was found that the flame absorption amounted to about 20 percent at $4.22 \mu$. This was measured by having one flame focused on the entrance slit and placing another flame in the path between the first flame and the entrance slit. The sum of the energies of the two flames burning separately was compared with the energy of the two flames burning at the same time. The corrected energy curve for the

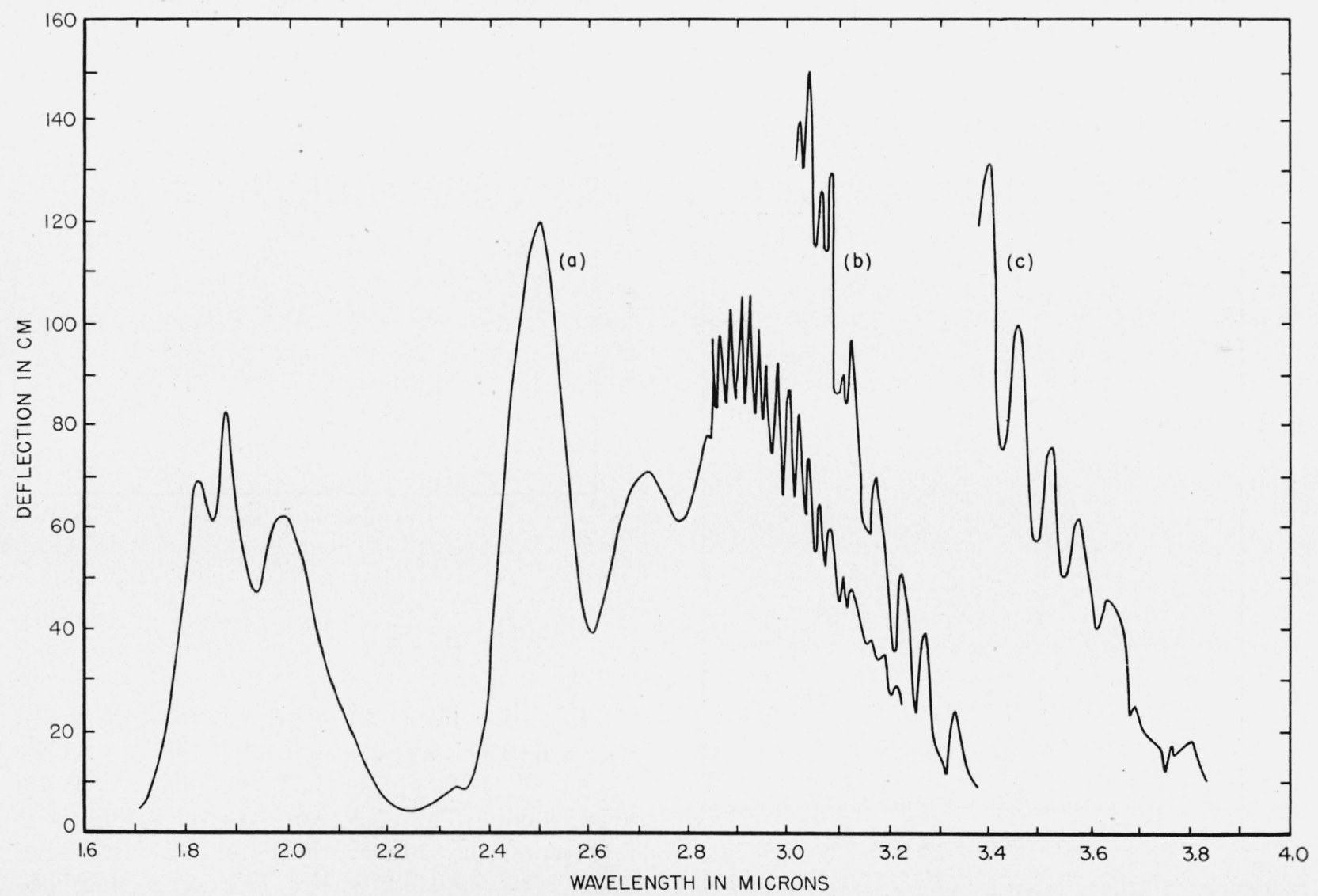

Figure 2. (a), Infrared emission spectrum of a hydrogen-oxygen flame. (b), Hotter flame and amplification increased 50 percent; (c), hotter flame and amplification increased 100 percent. 
$4 \mu$ to $5 \mu$ region did not vary by a significant amount from the curve shown in the previous paper (see footnote 2), and it is not shown here.

In figure 3 is shown the $6.26 \mu \mathrm{H}_{2} \mathrm{O}$ emission band. This was observed in the hydrogen flame with a considerable amount of oxygen. A rocksalt prism was used in the spectrometer, and the slits were $0.280 \mathrm{~mm}$ wide. There is very little emission in the center of the band, and the $R$ branch has maximum energy at $5.35 \mu$, and the $P$ branch at $6.75 \mu$. The rotational structure is not well resolved, but three strong lines can be seen between $7.5 \mu$ and $8.0 \mu$. The energy radiated by the flame is of low intensity. In figure 4 is shown the record of the energy emitted from $10 \mu$ to $15 \mu$ where it is a maximum. The position of the maximum of intensity within this region varies with the temperature of the flame. The energy emitted by the flame is very much dependent on the amount of oxygen that is introduced. For example, if the flame is hot, with a relatively high proportion of oxygen, the energy is about constant in the $10 \mu$ to $15 \mu$ region. For cooler flames with less oxygen, the energy increases continuously from $10 \mu$ to $15 \mu$. The marked changes in relative intensity of the rotational lines

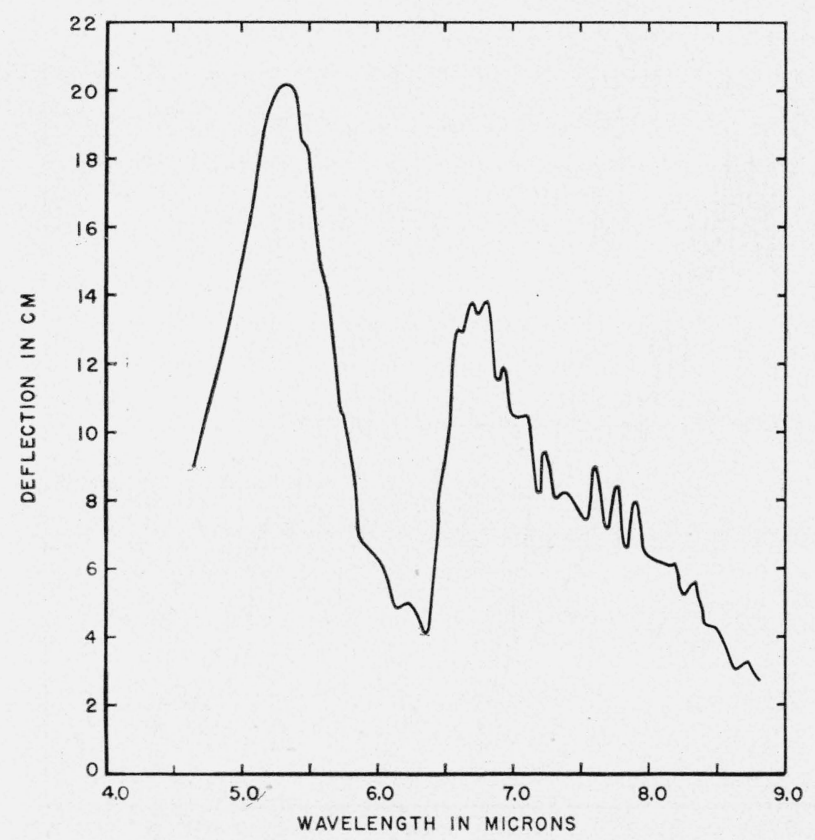

Figure 3. Emission spectrum of the $6.26 \mu$ band of the $\mathrm{H}_{2} \mathrm{O}$ molecule as obtained from a hydrogen-oxygen flame.

A rock salt prism was used, and the slits were $0.28 \mathrm{~mm}$ in width. of the water vapor molecule that are produced by flame changes may prove to be a method of measuring flame temperatures. However, no quantitative measurements were carried out on the relation between temperature and emitted energy. All observations were made in the portion of the flame above the cone, except when otherwise noted.

The rapid decrease in intensity of the rotational lines of the $\mathrm{H}_{2} \mathrm{O}$ molecule in the region from 13 to $15 \mu$ is caused largely by the absorption of the $\mathrm{NaCl}$ prism and by $\mathrm{CO}_{2}$ in the atmosphere. The results shown in figure 4 are for a flame exhibiting maximum intensity at about $12 \mu$. This flame was hotter than one showing constant energy, but the considerable drop in the observed energy in the $14 \mu$ to $15 \mu$ region is caused by absorption of the $\mathrm{NaCl}$ prism. This region of the spectrum was also observed with a $\mathrm{KBr}$ prism, and the envelope of the emission lines changed form with the temperature. For the hottest flames, the maximum intensity was observed at about $12 \mu$, and with cooler flames, the maximum intensity was at about $15 \mu$.

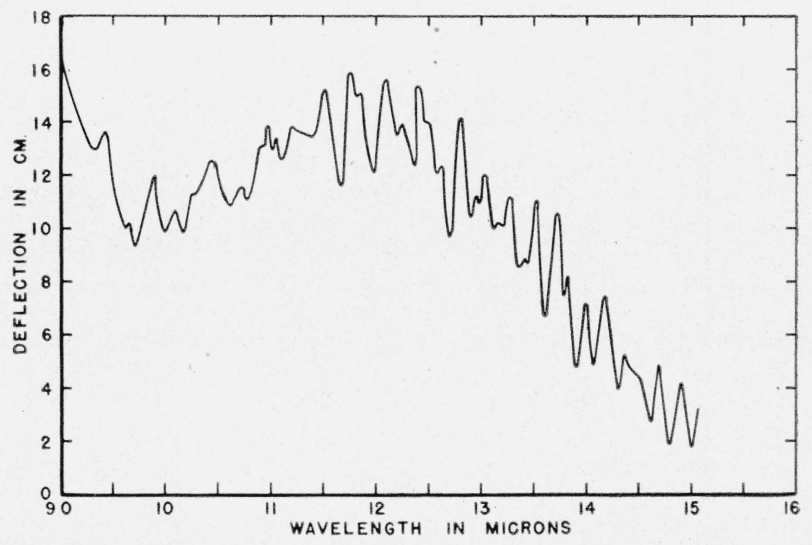

Figure 4. Rotational lines of the hydrogen-oxygen flame from 9 to $15 \mu$.

The slits were $0.5 \mathrm{~mm}$ wide, and an $\mathrm{NaCl}$ prism was used.

The region from $15 \mu$ to $24 \mu$ has been measured with a $\mathrm{KBr}$ prism and is shown in figure 5 . As the region of $24 \mu$ is approached, the energy becomes very small. The spectrum shown in figure 5 represents the observations on the hydrogen flame. Its emitted energy is greater than observed for the natural-gas flame, except in the region of $15 \mu$. 


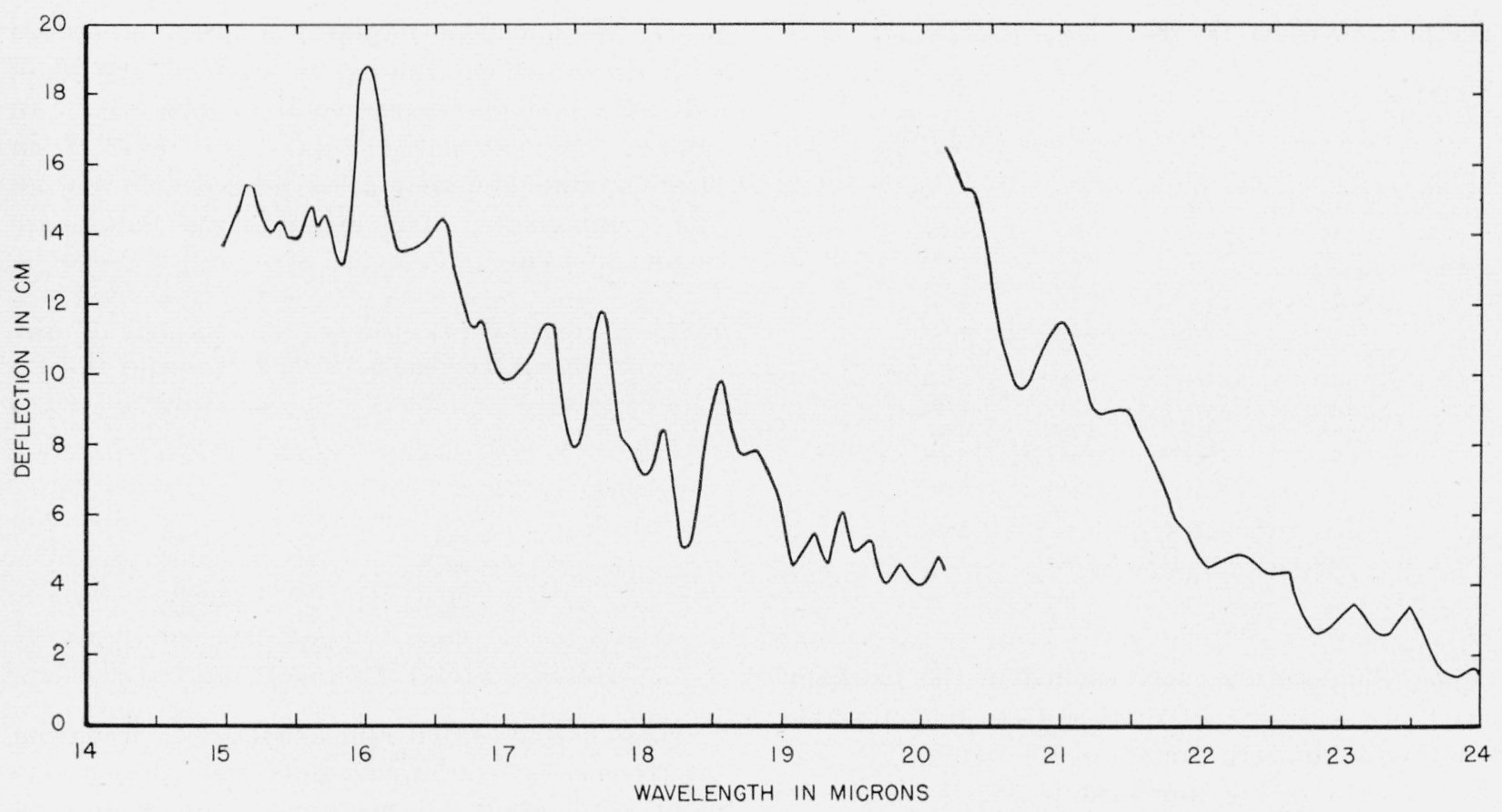

FIGURE 5. Rotational lines of the hydrogen-oxygen flame from 15 to $24 \mu$ measured with a $\mathrm{KBr}$ prism.

'The slits were $0.53 \mathrm{~mm}$ wide from 15 to $20 \mu$ and $0.7 \mathrm{~mm}$ from 20 to $24 \mu$.

\section{Discussion}

In the previous paper (see footnote 2), measurements of the Bunsen flame were reported, and the bands produced by the $\mathrm{CO}_{2}$ and $\mathrm{H}_{2} \mathrm{O}$ molecules were noted. Because of some overlapping of the two spectra, certain regions of the spectrum could not be well segregated. For this reason a comparison of the hydrogen-oxygen torch flame with the Bunsen natural-gas - air flame would assist in the study of the emission spectra of the $\mathrm{H}_{2} \mathrm{O}$ molecule. This is especially true of the region $1.7 \mu$ to $4.9 \mu$. The long wavelength branch of the $\mathrm{H}_{2} \mathrm{O}$ band at $2.7 \mu$ has been partially resolved, and about 19 lines can be seen in figure 2. By increasing the sensitivity of the instrument and increasing the temperature of the flame, lines are observed to about $3.8 \mu$. The lines from $3.3 \mu$ to $3.8 \mu$ are probably produced by $\mathrm{OH}$ and $\mathrm{H}_{2} \mathrm{O}$ molecules, but it has been found possible only in a limited region to make assignments from calculated values for transitions between the energy levels of either $\mathrm{H}_{2} \mathrm{O}$ or $\mathrm{OH}$. One exceptional instance will be discussed in another part of this paper. Higher resolution will be necessary in this region in order to permit accurate and complete assignment of lines to series.
It has been found that these lines check very closely with the series of $\Delta j=-1$ and $\Delta K=0$ for the $\mathrm{H}_{2} \mathrm{O}$ molecule and give rise to a spacing of about $20 \mathrm{~cm}^{-1}$. However, there are several other series to be expected corresponding to the higher rotational states of the $\mathrm{H}_{2} \mathrm{O}$ molecule, which would also give rise to lines in this region. So this one series may only, in part, explain the presence of these lines. The curves $b$ and $c$ of figure 2 show the effect of temperature on the lines, and the relative intensities are considerably altered. In table 1 the wavelengths and frequencies of the observed rotational lines are listed. Because of the high temperature of the flame, the rotationalvibrational bands have the energy reduced near the center and increased at larger rotational states. This causes the spread in frequency from the $P$ to $R$ maxima to increase. In the $R$ branch there is considerable crowding of the rotational lines.

The band at $3.316 \mu$ in figure 1 was observed at greatest intensity when the axis of a large cone of the flame was focused on the entrance slit of the spectrometer. The $R$ branch is readily recognized, but the $P$ branch of the band is weak. The zero branch is intense, and the region of maximum intensity is removed from the methane band, observed in absorption, by about $4 \mathrm{~cm}^{-1}$. As 
TABLE 1.-Observed rotational components in the region from 2.8 to $3.7_{\mu}$

\begin{tabular}{|c|c||c|c|}
\hline \hline Wavelength & $\begin{array}{c}\text { Wave num- } \\
\text { ber }\end{array}$ & Wavelength & $\begin{array}{c}\text { Wave num- } \\
\text { ber }\end{array}$ \\
\cline { 2 - 3 } & --1 & $\mu$ & $c m-1$ \\
2.827 & $c m-1$ & $\mu$ & \\
2.841 & 3,537 & 3.076 & 3,250 \\
2.855 & 3,502 & 3.100 & 3,225 \\
2.874 & 3,479 & 3.117 & 3,208 \\
2.895 & 3,454 & 3.063 & 3,161 \\
& & 3.216 & 3,109 \\
2.912 & 3,434 & 3.267 & 3,060 \\
2.929 & 3,414 & 3.325 & 3,007 \\
2.948 & 3,392 & 3.388 & 2,951 \\
2.971 & 3,365 & 3.448 & 2,900 \\
2.992 & 3,342 & 3.513 & 2,846 \\
& & & \\
3,013 & 3,318 & 3.568 & 2,802 \\
3.032 & 3,298 & 3.645 & 2,743 \\
3.056 & 3,272 & & \\
& & & \\
\hline
\end{tabular}

higher temperatures are reached in the methane gas there will be a gradual shift to longer wavelengths for the zero branch of the band.

The authors are indebted to G. H. Dieke of Johns Hopkins Univ., who furnished them with a table of the calculated wave numbers of the vibrational-rotational lines of $\mathrm{OH}$ and also the wave numbers for the pure rotational lines. ${ }^{4}$ Many lines arise from the $1 \rightarrow 0$ transition in vibrational levels and also from the $2 \rightarrow 1$ transition. The wave numbers calculated by Dieke were plotted, and it was found that the overlapping of the different series in the region from about 3,000 to $4,000 \mathrm{~cm}^{-1}$ was so great that the available instruments could not separate the different states. However, in the region from 2,500 to $3,000 \mathrm{~cm}^{-1}$, the overlapping is not so great, and a series of five lines that were observed in the hydrogen flame check will with predicted transition in the $2 \rightarrow 1$ vibrational band. The observed lines are shown in figure 2, c. With low oxygen concentrations in the mixture, these lines are very weak. The flame mixture was adjusted to give the greatest energy in this region, and it was a hot flame. When observations were made in the region of $3 \mu$, it was found that the lines as shown in figure 2 were not as well resolved with a hot flame as with a moderate flame. But as the longer wavelength region of the band is reached, high flame temperatures are necessary to bring out the rotational lines. The $2 \rightarrow 1$ band has $P$, $Q$, and $R$ branches and there are two series. Each line is double. Thus for each value of $K$ (rotational levels) there exist four lines with nearly the same wave number. It was not possible with the prism instrument to separate the lines, and only one maximum could be observed. In table 2 the calculated values are taken from Dieke's table, and they are averaged values of all four components. The experimental values are correct to $4 \mathrm{~cm}^{-1}$.

TABLE 2. Calculated and observed wave numbers for rotational lines in the $P$ branch of the $2 \rightarrow 1$ band of $\mathrm{OH}$

\begin{tabular}{|c|c|c|c|}
\hline$K$ & $\begin{array}{c}P \\
\text { (calculated) }\end{array}$ & $\begin{array}{c}P \\
\text { (observed) }\end{array}$ & $\begin{array}{c}P \\
\text { (observed) }\end{array}$ \\
\hline & $\mathrm{cm}^{-1}$ & $\mathrm{~cm}^{-1}$ & $\mu$ \\
\hline 11 & 2946.3 & 2,950 & 3. 388 \\
\hline 12 & 2897.9 & 2,896 & 3.448 \\
\hline 13 & 2848.9 & 2,848 & 3. 513 \\
\hline 14 & 2799.2 & 2,803 & 3. 568 \\
\hline 15 & 2748.8 & 2,744 & 3. 645 \\
\hline
\end{tabular}

These five lines that appear relatively free from interference or overlapping show such close agreement with predicted positions, that it appears practically certain that they constitute the part of the rotational structure of the $P$ branch of the $2 \rightarrow 1$ band of $\mathrm{OH}$, for $K$ values, 11 to 15 inclusive. This structure is observed only because the emission of the $\mathrm{H}_{2} \mathrm{O}$ molecules has become relatively weak in this limited interval. For the region of shorter wavelengths, the $\mathrm{H}_{2} \mathrm{O}$ emission is so strong as to completely mask the $\mathrm{OH}$ spectral structure so that it is not possible to observe lines showing the characteristic intervals for the $2 \rightarrow 1$ band and the $1 \rightarrow 0$ band.

In table 3 the wavelengths and wave numbers of the rotational lines from the hydrogen flame are listed. The observations to $15 \mu$ were made with an $\mathrm{NaCl}$ prism and from $15 \mu$ to $24 \mu$ with a $\mathrm{KBr}$ prism.

This table comprises all of the measured values of the emission maxima that appeared in the recordings of the spectrum of the hydrogen flame, shown in figures 4 and 5 . This observed spectrum appears to consist of the superposed systems of pure rotational lines of $\mathrm{OH}$ and $\mathrm{H}_{2} \mathrm{O}$.

In order to examine the evidence that the rotational $\mathrm{OH}$ emission spectrum has been produced, table 4, giving a comparison of the calculated and observed line positions, has been constructed. The calculated wave numbers, corresponding to $K$ values 11 to 22 , are obtained from Dieke's table.

\footnotetext{
${ }^{4}$ G. H. Dieke, Table of $\mathrm{OH}$ bands, private communication.
} 
TABLE 3. Observed rotational lines in the spectrum of the hydrogen flame in the region from 9 to $24 \mu$

\begin{tabular}{|c|c|c|c|c|c|}
\hline $\begin{array}{c}\lambda(\mu) \\
(\text { ob- } \\
\text { served) }\end{array}$ & $\begin{array}{c}\mathrm{cm}^{-1} \\
\text { (ob- } \\
\text { served) }\end{array}$ & $\begin{array}{c}\lambda(\mu) \\
(\text { ob- } \\
\text { served) }\end{array}$ & $\begin{array}{c}\mathrm{cm}^{-1} \\
\text { (ob- } \\
\text { served) }\end{array}$ & $\begin{array}{c}\lambda(\mu) \\
(\text { ob- } \\
\text { served) }\end{array}$ & $\begin{array}{c}\mathrm{cm}^{-1} \\
\text { (ob- } \\
\text { served) }\end{array}$ \\
\hline 9.43 & 1,060 & 13.43 & 745 & 20.11 & 497 \\
\hline 9.63 & 1,038 & 13.53 & 739 & 20.41 & 490 \\
\hline 9.89 & 1,011 & 13. 70 & 730 & 20.98 & 477 \\
\hline 10.07 & 993 & 13.83 & 723 & 21.47 & 466 \\
\hline 10.03 & 970 & 13.99 & 714 & 21.91 & 456 \\
\hline 10.44 & 958 & 14.17 & 706 & 22. 26 & 449 \\
\hline 10. 73 & 931 & 14.35 & 697 & 22.63 & 442 \\
\hline 10.90 & 917 & 14.49 & 690 & 23.08 & 433 \\
\hline 10.98 & 911 & 14.68 & 681 & 23.50 & 426 \\
\hline 11.04 & 905 & 14.91 & 671 & 23.96 & 417 \\
\hline 11.19 & 894 & 15.16 & 659 & & \\
\hline 11. 54 & 867 & 15.35 & 652 & & \\
\hline 11. 75 & 851 & 15.61 & 641 & & \\
\hline 11.85 & 844 & 15.70 & 637 & & \\
\hline 12.09 & 827 & 16.01 & 625 & & \\
\hline 12.25 & 816 & 16.58 & 603 & & \\
\hline 12.41 & 806 & 16.82 & 595 & & \\
\hline 12.48 & 801 & 17.31 & 578 & & \\
\hline 12.63 & 791 & 17.70 & 565 & & \\
\hline 12.79 & 781 & 18.13 & 552 & & \\
\hline 12.94 & 772 & 18.54 & 539 & & \\
\hline 13.03 & 767 & 18. 79 & 532 & & \\
\hline 13.14 & 761 & 19. 22 & 520 & - & 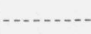 \\
\hline 13.28 & 753 & 19.43 & 515 & & \\
\hline
\end{tabular}

Actually there are four possible lines for each $K$, but inasmuch as the resolution available in these experiments did not permit observation of these separate components, the four values are averaged in each instance to give the computed line position. Dieke's calculations were carried out only as far as $K$-value, 22. We have extended them to $K$, 36 , by extrapolation. It is estimated that the error in this extrapolation cannot exceed $1 \mathrm{~cm}^{-1}$, which is well within the estimated experimental error of the observations for this region of the spectrum, namely $4 \mathrm{~cm}^{-1}$.

Of the 26 entries in table 4 , all but 2 show agreement between the observed and calculated positions within the limits of experimental error. In almost all instances of failure to find experimental evidence for an emission line of $\mathrm{OH}$, there is an intense maximum probably originating in $\mathrm{H}_{2} \mathrm{O}$ overlapping the calculated position. Some of the listed lines appear only as bulges on the sides of the profiles of other intense maxima, but agreement with the predicted position seems to confirm their reality. The evidence for the reality of this system of rotational lines of $\mathrm{OH}$ rests mainly on its completeness rather than on the precision of the
TABLE 4. Observed and calculated wave numbers of the pure rotational lines of $\mathrm{OH}$

\begin{tabular}{|c|c|c|c|}
\hline$K$ & $\begin{array}{c}R \\
\text { (calculated) }\end{array}$ & $\begin{array}{c}R \\
\text { (observed) }\end{array}$ & $\begin{array}{c}R \\
\text { (observed) }\end{array}$ \\
\hline & $c m-1$ & $\mathrm{~cm}^{-1}$ & $\mu$ \\
\hline 11 & 431.8 & 433 & 23.08 \\
\hline 12 & 465.3 & 466 & 21.47 \\
\hline 13 & 498.4 & 497 & 20.11 \\
\hline 14 & 530.9 & 532 & 18. 79 \\
\hline 15 & 562.7 & 565 & 17.70 \\
\hline 16 & 593.8 & 595 & 16. 82 \\
\hline 17 & 624.2 & 625 & 16.01 \\
\hline 18 & 653.9 & 652 & 15.35 \\
\hline 19 & 682.9 & 681 & 14.68 \\
\hline 20 & 711.0 & 714 & 13.99 \\
\hline 21 & 738.3 & 739 & 13.53 \\
\hline 22 & 764.8 & 767 & 13.03 \\
\hline 23 & 790.6 & 791 & 12.63 \\
\hline 24 & 815,6 & 816 & 12.25 \\
\hline 25 & 839.9 & 844 & 11.85 \\
\hline 26 & 863.4 & 867 & 11.53 \\
\hline 27 & 886.2 & 886 & 11. 28 \\
\hline 28 & 908.2 & 911 & 10.98 \\
\hline 29 & 929.5 & 931 & 10. 73 \\
\hline 30 & 950.0 & -.. & -.... \\
\hline 31 & 969.8 & 970 & 10.31 \\
\hline 32 & 988.8 & 993 & 10.07 \\
\hline 33 & 1007.0 & 1,011 & 9.89 \\
\hline 34 & 1024.5 & -.. & -.... \\
\hline 35 & 1041. 2 & 1,038 & 9.63 \\
\hline 36 & 1057.2 & 1,060 & 9.43 \\
\hline
\end{tabular}

observations. The appearance of a small number of scattered combinations dispersed through another complex spectrum might well be regarded as fortuitous, but when the observed system is practically complete, the probability that it is real seems to be overwhelming.

The numerous remaining lines shown in figures 4 and 5 and listed in table 3 , are produced by higher rotational states of the $\mathrm{H}_{2} \mathrm{O}$ molecule. As mentioned above; some of these overlap or coincide with $\mathrm{OH}$, making it practically impossible to estimate the relative intensities of the lines in the $\mathrm{OH}$ system. A noteworthy instance is the very intense maximum at $16.0 \mu$, which undoubtedly receives by far the greater contribution from $\mathrm{H}_{2} \mathrm{O}$, masking an $\mathrm{OH}$ line in the same location.

\section{Conclusion}

The emission spectra of a gas-oxygen and hydrogen-oxygen flame have been compared in the region from $1.7 \mu$ to $3.8 \mu$. Nearly all of the energy in the $1.9 \mu$ region is produced by the $\mathrm{H}_{2} \mathrm{O}$ molecule. A small increase in the energy of the gas flame in 
the $2-\mu$ region may be caused by emission of $\mathrm{CO}_{2}$. The rotational lines that are observed at about $3 \mu$ are present in both flames, but they extend to longer wavelengths in hydrogen-oxygen flames. The intensity of the observed bands can be increased at least twofold by increasing the oxygen. The emission in the region of $10 \mu$ can be greatly increased with high-temperature flames. The energy remains about constant from $9 \mu$ to $16 \mu$ and then decreases gradually to $24 \mu$. With a moderate flame temperature the energy increases from $9 \mu$ to $15 \mu$ and then decreases as the wavelength is increased.

In this study of the emission of flames, it has been shown that the amount of oxygen that is introduced into the flame has marked influence on the intensity of the band. In the $3-\mu$ region, the relative intensities of the rotational lines may be varied considerably by changing the temperature of the flame. For a quantitative study of emission spectra originating in a flame, it would be necessary to measure the quantity of fuel gas and oxygen that are mixed for burning. A gas-oxygen torch or a regulated burner, giving rise to a steady flame, makes it much easier to obtain smooth traces on the recorder for the energy emitted. The results can be repeated closely. For quantitative determinations, the steady flame is very desirable. However, in many industrial applications, the turbulent flame is the more common type, and the Bunsen burner flame approaches nearer to industrial burner flames. This study has been chiefly concerned with the study of the emission spectra of $\mathrm{CO}_{2}$ and $\mathrm{H}_{2} \mathrm{O}$ in flames. The flames resulting from burning various hydrocarbons and alcohols will also have considerable energy emitted by $\mathrm{CO}_{2}$ and $\mathrm{H}_{2} \mathrm{O}$ molecules. There may be other bands in the observed flame spectra of various fuels that are characteristic of the molecular or atomic groups. The bands are usually of low intensity.

In addition to a controlled burner, a spectrometer of high aperture ratio is needed. This makes it possible to observe low-intensity bands. Because of the decrease in the observed intensity produced by the absorption of $\mathrm{H}_{2} \mathrm{O}$ and $\mathrm{CO}_{2}$ molecules in the air, an instrument that is free from atmospheric absorption is better suited for quantitative measurements. For the study of many problems, an instrument of moderate resolution is satisfactory. In the measurement of the rotational lines within a band, a grating spectrometer is better suited.

The authors express their thanks to G. H. Dieke of Johns Hopkins University for supplying calculated values of the wave numbers of the $\mathrm{OH}$ bands and of W. S. Benedict of the National Bureau of Standards for advice in the interpretation of the experimental data.

Washington, March 12, 1948. 